\title{
A mediação da imprensa paulista na construção da imagem da Amazônia: uma análise comparativa de dois períodos históricos, a ditadura e a democracia*
}

\author{
Grace Ane Lauxen Stefanello**
}

\begin{abstract}
Resumo:
Este trabalho apresenta parte da pesquisa de doutorado, em fase de conclusão, que tem como objetivo central analisar o tratamento comunicativo da Amazônia dado pela imprensa escrita paulista. Estando o presente estudo enfocado nas representações dos produtos comunicativos, considera-se que o tratamento dado pelas instituições mediadoras a determinados acontecimentos depende do tipo de formação sócio - política dominante e que, ao mesmo tempo, esse tratamento poderia estar construindo uma realidade social que incidisse no mesmo plano sócio - político. O trabalho tem como referencial teórico o Paradigma da Mediação e a Teoria Social de Comunicação. $\mathrm{O}$ método utilizado é o de Análise de Conteúdo de notícias publicadas nos jornais Folha de $\mathrm{S}$. Paulo e $\mathrm{O}$ Estado de $\mathrm{S}$. Paulo durante a Ditadura e a Democracia.

Palavras-chave: representação da Amazônia na imprensa, mediação dos meios, inter-relação entre sistema comunicativo e sistema político.
\end{abstract}

\section{Introdução}

A importância que têm no Brasil os temas relacionados com a Amazônia é um dos argumentos principais que orientaram a abordagem desta pesquisa, a qual está centrada no tratamento comunicativo oferecido pela imprensa escrita paulista a este tema de grande interesse para a sociedade. A Amazônia, no imaginário coletivo dos brasileiros, passou de ser considerada uma região geográfica com algumas

* Trabalho apresentado no V SIPEC - Simpósio de Pesquisa em Comunicação do Centro-Oeste, realizado em Goiânia, no período de 20 a 22 de maio de 2000.

** Bacharel em Comunicação Social pela PUC/RS, doutoranda do programa de Teoria da Comunicação e Metodologia da Pesquisa na Universidade Complutense de Madri.

Comun. Inf., v. 3, n. 1, p. 56-64, jan./jun. 2000 
conotações determinadas, transformando-se numa realidade multivariada e numa das questões mais controvertidas da política nacional. Neste estudo considera-se que a comunicação produzida através dos M.C.M constrói uma realidade pertinente aos interesses dopoder estabelecido, mostrando uma imagem partidária. Essa imagem é variável, sendo construída em função das demandas expressas do poder. Considera-se ainda que a própria dinâmica comunicativa pode exercer sua influência nos discursos e comportamentos sócio-políticos. Nesse sentido, política e comunicação aparecem como duas dimensões dessa realidade que se inter-relacionam ${ }^{1}$.

\section{Objetivos}

Com esta pesquisa pretende-se descobrir algumas respostas que expliquem as relações entre os processos comunicativos e políticos. Para tanto, será necessário:

- Analisar as possíveis transformações que se produziram nos relatos, ao substituir-se um regime ditatorial por um democrático;

- Avaliar como os M.C.M, influenciados pelo poder político, podem contribuir para a construção da realidade, atendendo a interesses concretos;

- Identificar os modelos de mediação que a imprensa escrita utiliza para informar sobre a realidade amazônica;

- Avaliar as semelhanças e diferenças nos conteúdos das notícias divulgadas durante um e outro período;

- Identificar as ideologias ocultas no discurso dos jornais analisados;

- Identificar as reproduções e as mudanças nos relatos produzidas nos dois períodos.

\section{Metodologia utilizada}

O método utilizado é o de Análise de Conteúdo, relevante para o estudo da realidade social mediante a observação e análise estatística dos dados oriundos de documentos, livros ou materiais procedentes dos M.C.M. Este tipo de análise oferece a possibilidade de tratar a informação de maneira metódica, descompondo um discurso mediador e reconstruindo-o com outra ordem, a fim de revelar um sentido implícito no relato.

Comun. Inf., v. 3, n. 1, p. 56-64, jan./jun. 2000 
3.1 Os âmbitos de referência sobre a Amazônia.

O universo de estudo

O objeto de análise deste estudo é todo material informativo que contenha informação sobre a Amazônia, publicados nos jornais Folha de S. Paulo e O Estado de S. Paulo, nos períodos políticos da ditadura e da democracia.

A análise dos referentes centrou-se em três grandes âmbitos de estudo:

- Acontecimentos de natureza sócio-política;

- Acontecimentos de natureza econômica e de relações internacionais; $\mathrm{e}$

- Acontecimentos de natureza ecológica ou ambiental.

\subsection{Unidades de análise}

As unidades de análise escolhidas para esta pesquisa foram:

- Unidade de amostragem (a notícia);

- Unidade de contexto ( documento inteiro, ou seja, todo o jornal); e

- Unidade de registro (o acontecimento e o personagem).

\subsection{Variáveis de estudo}

Para este estudo foi elaborado um protocolo de análise. O protocolo serve para transformar o conteúdo dos textos em informação codificada para ser analisado informaticamente. Com o protocolo pretende-se conhecer que tipo de acontecimentos foram selecionados e os personagens (características dos personagens) que aparecem nos relatos, entre outras informações. O Fluxograma apresentado na Figura 1 mostra o modelo de análise elaborado para esta pesquisa. Veja na página seguinte:

Comun. Inf., v. 3, n. 1, p. 56-64, jan./jun. 2000 
Alguns emissores elaboram relatos na imprensa escrita, onde fazem referência a algum acontecimento e mencionam algum personagem.

Elegem:

um Acontecimento de Referência no jornal A - no período $A$ no jornal $B$ no período $B$

onde é mencionado

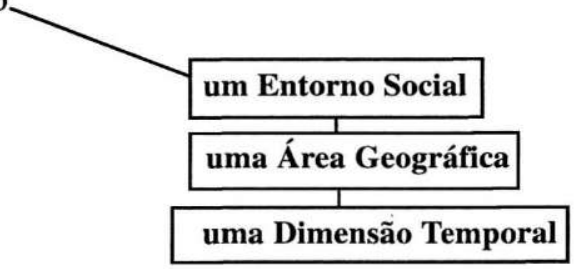

No relato se menciona algum personagem que

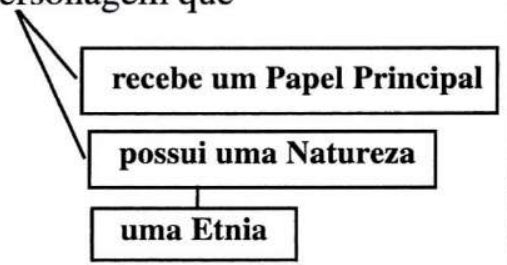

O personagem:

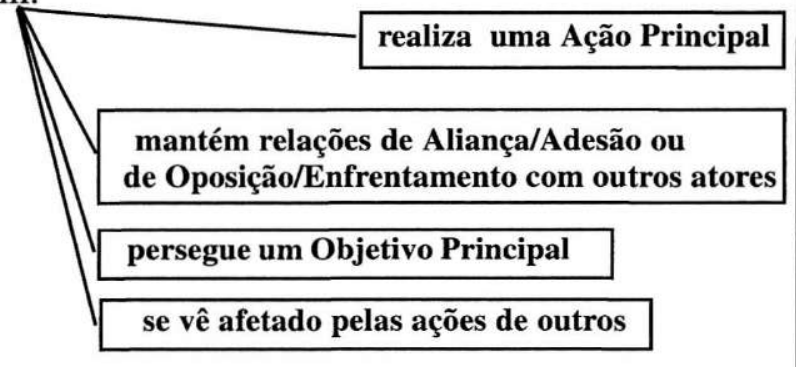

Tais relatos são destinados a uns receptores específicos, que são os leitores.

Figura 1 - Modelo de ANÁLISE

Comun. Inf., v. 3, n. 1, p. 56-64, jan./jun. 2000 
3.4 O tratamento dos dados. Análise estatística

Os dados obtidos das diferentes unidades de análise foram processados em dois níveis:

a) Análise Estrutural: das variáveis e categorias primárias foram elaboradas novas variáveis ou variáveis derivadas, assim como novas categorias procedentes da desagregação ou agrupamento por analogia. Trata - se de elaborar sistemas de classificação de variáveis e categorias, seguindo critérios estruturais e lógicos.

b) Análise Estatística: o tratamento dos dados foi feito de três maneiras:

- Análise de distribuição de frequiências, através de um enfoque unidimensional, fazendo-se uma contagem das freqüências e porcentagens das variáveis simples;

- Análise de associação ou de contingência, através de um enfoque bidimensional de cruzamento entre duas variáveis, buscando-se as freqüências e porcentagens e verificando-se a significação dos dados. Segundo o desenho de análise, cada variável se cruzará com as de controle e com as que se espera alguma associação; e

- Análise de associação multivariável, através de cruzamentos entre três variáveis, seguindo os mesmos critérios empregados na análise de contingência.

\section{Apresentação e análise parcial dos resultados}

\subsection{Características da representação da Amazônia na imprensa}

As pautas narrativas associadas à Amazônia são muito tópicas e os relatos se desenvolvem segundo macroarquétipos em que se movem a maior parte das narrações. Pode-se observar três modelos de representação da Amazônia:

- A Amazônia Institucionalizada;

- A Amazônia Violenta, e

- A Amazônia Mito Ecológico.

O fato de a imprensa paulista abordar a realidade amazônica desde o ponto de vista "institucional" e a questões relacionadas à "violência", pode estar relacionado com:

Comun. Inf., v. 3, n. 1, p. 56-64, jan./jun. 2000 
- A própria realidade amazônica, que historicamente esteve vinculada a acontecimentos conflituosos, principalmente conflitos territoriais incrementados pelos grandes planos dos militares para a colonização da Amazônia.

- Ao grande interesse sobre esse território, sobretudo econômico, tanto por empresas nacionais como multinacionais; $\mathrm{e}$

- O fato de a Amazônia ser discutida, em geral, na imprensa em termos econômicos e relacionada a grandes instituições.

A falta de abordagem da realidade amazônica de uma perspectiva meio ambiental pode estar associada ao pouco interesse pelas questões ambientais. Apesar de ter sido na década de 70 que surgiu o termo "desenvolvimento sustentável" foi nos anos 80 que esta corrente ganhou maior amplitude. O que se pode constatar é que esses modelos de representação da Amazônia passam uma visão pobre e estereotipada.

A televisão e a imprensa difundem modelos de comportamento muito distintos e designam um repertório de papéis a seus personagens, de acordo com as pautas ou mundos relatados. Os protagonistas que com maior freqüência aparecem nos relatos amazônicos são os "políticos-líderes" relacionados com a própria característica do meio imprensa mais especializado no mundo sóciopolítico. Daí a sua grande preferência pelos personagens públicos.

É interessante observar que a imprensa não dá um especial protagonismo ao indígena porque, em geral, o personagem protagonista é um sujeito relacionado a alguma instituição, ao governo ou a políticos. Esses personagens realizam ações conflituosas de "denúncias e conflitos". Isso vai de encontro às próprias pautas narrativas dominantes, que estão relacionadas à violência e às instituições.

\subsection{Representação da Amazônia nos períodos políticos da Ditadura e da Democracia}

$\mathrm{Na}$ ditadura, a tendência dos relatos é a de tratar de "violência" e "implicações institucionais" em maior número que na democracia. No entanto, temas relacionados ao meio ambiente são mais numerosos na democracia, coincidindo com a introdução, na mídia, do discurso ambiental.

Comun. Inf., v. 3, n. 1, p. 56-64, jan./jun. 2000 
A imprensa paulista utiliza nos seus discursos noticiosos quatro grandes grupos de protagonistas que aparecem com róis de "líderespolíticos", "judiciais-governamentais", "criminais", e "investigadorecologista". O rol de criminoso geralmente está identificado com o indígena e em oposição está o arquétipo institucionalizado do sujeito "judicial-governamental", encarregado de submeter e dominar as ações daqueles. Trata-se de um confronto entre a ordem social versus desviação social. Ambos os estereótipos geralmente coincidem na mesma notícia. É a ordem social mediando restritivamente a desviação social. A imprensa assinala o protagonismo do juiz, do governador ou de qualquer outra figura institucional sobre a figura do delinqüente ou do indígena. $\mathrm{O}$ rol de liderança que desempenham alguns personagens políticos vem a configurar uma segunda via "arquetípica" mais relacionada com a atuação governamental. Os profissionais, como terceiro arquétipo predominante, nos remetem à importância dada ao "investigadorecologista", entendido este como um novo herói nos relatos que aparecem nos últimos anos, num contexto de uma visão de mundo centrada nas preocupações derivadas da ecologia. Por tudo isso, pode-se compreender que durante a ditadura o herói principal era o político e o jurista, em oposição ao anti-herói representado pelo indígena, enquanto que durante a democracia o novo herói que se sobressai nos relatos é o científico, preocupado com o meio ambiente e, portanto, difusor do até então anti-herói indígena, que no novo período começa a assumir um novo rol de quase herói.

A segunda dimensão do conteúdo informativo analisado referese à ação que vem determinada pela própria identidade do protagonista. Os sujeitos que possuem uma determinada identidade, construída através de seus próprios róis ou funções sociais, sempre realizam alguma ação que se corresponde com o papel que desempenham na sociedade. Pode-se observar uma clara correspondência dos sujeitos com as ações que realizam os personagens das informações. Neste estudo, esperava-se que o arquétipo do "líder-político" mostrasse nos relatos um tipo de comportamento relacionado a ações de "projetos e propostas", sejam elas de tipo legislativo, normativo ou de persuasão propagandista. Diante da figura do anti-herói, representado fundamentalmente pelo indígena que realiza atos conflituosos, aparece a figura do herói judicial e policial que realiza ações policiais

Comun. Inf., v. 3, n. 1, p. 56-64, jan./jun. 2000 
e que se encarrega de reprimir a desviação social e de colocá-la a juízo. A imprensa acaba decidindo-se ou inclinando-se pela reprodução desse estereótipo como reflexo da própria reprodução social. Algo deve ter mudado durante a democracia quando o papel do novo herói "científico-investigador" introduz novos comportamentos consensuais, onde as investigações, encontros, "projetos e propostas" começam a substituir ações do passado.

Finalmente, observa-se que na época da ditadura o discurso ambientalista que predominava era o tecnocêntricoconservacionista ${ }^{2}$. Esse discurso considera que os recursos naturais não são limitados, destacando o direito das atuais gerações de usufruírem dos recursos da natureza. A natureza - neste caso específico, a Amazônia - era um adversário a ser conquistado. $\mathrm{Na}$ democracia, a perspectiva tecnocêntrica segue em pauta, mas falase em desenvolvimento sustentável, já que os recursos naturais passam a ser considerados limitados, e destaca-se a necessidade do desenvolvimento de uma consciência ecológica. Nesse período, a imprensa paulista passa a acrescentar aos seus discursos sobre a realidade amazônica a questão ambiental, sendo o tema ecologia um gerador de notícias.

\section{Agradecimentos}

A autora agradece a CAPES o financiamento desta pesquisa, aos professores do departamento de Sociologia IV da Universidade Complutense de Madri e ao prof. Dr. Manuel Martín Serrano, orientador da investigação.

\section{Abstract}

This work presents part of the doctorate research being concluded that has as main objective analyse the communicative treatment of the Amazon Forest given by the paulista written press.

Being the current study focused in the representations of the communicative products, it's considered that the treatment given by the mediator institutions to established happenings, depends of the type of the formation socio-political dominant and that, at the same time, this treatment could be building a social reality that happened in the same socio-political plan. The work has a theoretical reference the Mediation Paradigm and the Social Theory of Communication.

Comun. Inf., v. 3, n. 1, p. 56-64, jan./jun. 2000 
The method used is the Analysis of content of news published in the newspapers Folha de São Paulo and $O$ Estado de São Paulo during the Dictatorship and the Democracty.

Kew words: representation of the Amazon Forest in the press, mediation of the means, inter-relation between Communicative System and Political System.

\section{Notas}

1. A perspectiva teórica adotada neste trabalho é a do Paradigma da Mediação e a Teoria Social de Comunicação, que foi exposta pelo professor Manuel Martín Serrano, em 1977 e em 1986.

2. A esse respeito podem-se obter maiores informações no trabalho de Guedes, O., O discurso ambientalista na mídia brasileira. Olhar Midiático:R. Comunic. Inf. da Univ. Fed. Ceará, Fortaleza, n. 1, p. 7-14, mar. 1998. Nesse trabalho, a autora apresenta as duas principais tendências político-filosóficas mais influentes na literatura da ecologia política.

\section{Referências}

GUEDES, O. O discurso ambientalista na mídia brasileira. Olhar Midiático: R. Comunic. Inf. da Univ. Fed. Ceará, Fortaleza, n. 1, p. 7-14, mar. 1998.

PEREIRA, M. J. Prensa del estado durante la transición política española. Madrid: CSIC, 1989.359p.

SERRANO, M.M. La mediación social. Madrid: Akal, 1977.217p.

SERRANO, M.M. La producción social de comunicación. Madrid: Alianza, 1986.501p.

SPÁ, M.M. Teorías de la comunicación: investigación sobre medios en América y Europa. México: Gustavo Gilli, 1991.325p.

STEFANELLO, G.A.L. A construção da imagem da Amazônia na imprensa escrita paulista. Madri: Universidade Complutense de Madri. Tese de Doutorado em andamento.

VAN DIJK, T.A. La noticia como discurso: comprensión, estructura y producción de la información. Barcelona: Paidós, 1990. 284p. 